\title{
INTEGRATED OPERATIONS: A PROPOSAL FOR OPERATIONS MANAGEMENT TEACHING AND RESEARCH*
}

\author{
WILLIAM S. LOVEJOY \\ University of Michigan Business School, 701 Tappan, Ann Arbor, \\ Michigan 48109-1234, USA
}

\begin{abstract}
This paper, addressed to professors of operations management (OM) in research institutions, suggests that the long-term academic viability of our discipline requires the generation of a theory uniquely associated with the practice of $\mathrm{OM}$. Such a theory will rest on foundations laid by other disciplines, but must find its own unique synthesis that attends to the problems of om practice. The paper proposes a framework that recognizes physics, social psychology and philosophy as foundational disciplines for an integrative theory of om and suggests which concepts from those disciplines may find voice in such a theory.

(OPERATIONS MANAGEMENT; INTEGRATED OPERATIONS; CROSS-FUNCTIONAL TEACHING AND RESEARCH)
\end{abstract}

\section{Introduction}

This paper is addressed to professors of operations management (OM) teaching in research institutions. I will treat teaching and research as an inseparable pair, for the philosophical and practical reasons articulated below. I will then propose that the task before us is to craft a theory of $O M$ that is more inclusive of broader, cross-functional issues than is currently the case and is responsive to the multidimensional nature of industrial reality.

I believe that $\mathrm{OM}$, residing at the technological core of the firm, is ideally situated to pick up the cross-disciplinary mantle. However, I am not proposing that oM try to become the encyclopedic discipline, replicating completely the functional depth and nuance achieved in each of several contributing fields. Rather, the challenge is to distill from those disciplines the major concepts that will contribute to a holistic framing of oM, much as operations research (OR) distills from engineering and economics the tools that are uniquely valuable in the practice of $\mathrm{OR}$. In the end, we need a synthesis that is uniquely associated with oM, not just a compendium of current work in other fields.

In this paper I defend these claims and begin the process of recommending which concepts should find voice in a unified theory of oM.

\section{A. What is Operations Management?}

Operations Management is the selection and management of transformation processes that create value for society. Our goal as instructors is to prepare students to contribute more effectively to improving society through their practice of ом.

\footnotetext{
* Received April 1996; revision received November 1996; accepted December 1996.
} 
$\mathrm{OM}$ as a field has both theoretical and craft (gained only through practice) dimensions. Ideally, the theory must inform and improve the practice of OM. As I have stated, my assumed audience is professors of OM in research-oriented schools. By research-oriented I mean an organization dedicated to both knowledge creation and communication. My restriction to research institutions carries with it a corollary obligation, that of developing a theory of OM. It is not sufficient to teach only the craft. This restriction is based on four realities:

1. The philosophical reality: Our goal is to better prepare students for the practice of OM, not just today but for years into the future. A theory, which imparts a deeper understanding of why things are as they are, better prepares students to apply knowledge in changing circumstances.

2. The practical reality: Our ability to teach oM is greatly facilitated if we can communicate our knowledge in a systematic and consistent fashion. A theory informs the taxonomies we use and frames our discourse in oM.

3. Political reality: In a research institution, the viability of a field is only guaranteed if there is a theory uniquely associated with that field. Reports to the Ford and Carnegie Foundations in the 1950 s called business education to task for being too heuristic and not sufficiently rooted in any theoretical base (cf. Schmotter 1984). Since then, business schools have attained academic respectability primarily by rooting their knowledge in strong disciplinary theories. The current problems with relevance notwithstanding, it would be a mistake to argue that we should go back to emphasizing technical skill at the expense of a theoretical base. A discipline without a theory has no natural constituency in a research institution.

4. Competitive reality: With emerging technologies, the dissemination of information in the future might well take place in a manner nothing like the current, physically and chronologically co-located classroom. Consulting firms, businesses, and other organizations might enter the "information for profit" industry. I would claim that a sustainable competitive advantage of the current university structure is theory formation and that we as scholars leverage our strengths by committing ourselves to this activity.

Operations has historically been dominated by technical design and control issues. This derives from the industrial engineering and $O R$ heritage shared by many of the current faculty in om departments across the country. But, the time has come for our field to take a broader view of the entire spectrum of considerations that must attend successful oM practice. This is not a proposal to abandon $O R$ (far from it, see below), but a call to expand our theoretical base to attend to the spectrum of challenges facing our field and function. In the following I suggest which foundational disciplines, and what concepts from those disciplines, can be used as a point of departure in theory formation. First, however, the nature of theory itself needs to be examined briefly.

\section{B. What is Theory?}

The American Heritage Dictionary (1985 version) defines theory as "systematically organized knowledge applicable in a relatively wide variety of circumstances, esp. a system of assumptions, accepted principles, and rules of procedure devised to analyze, predict, or otherwise explain the nature or behavior of a specified set of phenomena."

A theory is a claim as to why things are as they are. It is important to note what a theory is not. A classification scheme or taxonomy will categorize knowledge, but is not a theory because it does not explain why things are as they are. A good classification scheme will always be informed by theory, because we choose to put different items in different sets for a reason, and that reason is based in theory (cf. Hooker 1991). But a taxonomy is not itself a theory.

Also, continuing with arguments presented by Hooker, reporting behaviors (protocol analysis) is not a theory. The difference can be illustrated by considering a researcher 
cataloging the actions of chemists. A reporting of these actions is a description of how practitioners behave, but is not a theory, of chemistry. A theory must tell us why certain actions or initiatives will have specified results.

Finally, empirical results in isolation do not constitute a theory. Empirical observations tell us how things are. Empirical research is critical to our understanding of our field, and indeed in the absence of theory, statistical relationships and benchmarking provide value by providing information for decision-making. Yet, empirical research, the study of how things are, must be extended to an explanation of why they are as they are. Absent this, it is not theory. We will see below, however, that empirical relationships can contribute to the axiomatic foundations that a theory uses in deriving its results. That is, the answer to "why" something happens can in part invoke a compelling and commonly held relationship that has earned its credibility from empirical observation.

When we state the reasons why certain phenomena occur, we could go further to ask why these reasons are sufficient to explain the phenomena. We can continue to ask "why?" at each level of inquiry. This moving backward through layers of logic, asking why and after each response asking why again, is called the "regression of theory." When can we stop? When does this collection of "why's" become a theory? Where we stop would seem to derive from our faith that the relationship is "applicable in a relatively wide variety of circumstances" and when we understand the specific assumptions on which our claims rest. The assumptions on which our claims rest may themselves be derivable from more general principles or may be assumptions based on compelling empirical evidence.

That is, theories can rest on a combination of more fundamental theories and compelling empirical relationships, providing these building blocks are used to explain higher level phenomena. For example, OR is a synthesis of engineering and economics, and engineering combines applied physics and mathematics. Many aspects of these disciplines can be traced through many layers of logic to fundamental physical and mathematical axioms. In contrast, the social sciences have not achieved a comparably deep logical construction, and its theories rely on assumptions that are relatively closer to the surface.

A theory of OM can be a synthesis of contributing theories from other fields. Below I suggest what those fields might be. Although this paper takes the perspective that it is always better to push the regression of theory back as far as one can and not stop at an observed relationship until forced to by the current state of knowledge in an area, it remains true that the intimate and self-reinforcing relationship between theory and empiricism in $\mathrm{OM}$ will and should continue to characterize our field.

\section{What is a Theory of Operations Management?}

A theory of operations management will be a systematically organized knowledge base uniquely associated with the design and management of transformation processes to create value for society. It must tell us not just how things are, but why they are as they are; its explanations must rest on compelling axioms or assumptions; it must be applicable in a relatively wide array of circumstances; and it must inform practice by impacting the valuegenerating activities that are its subject.

A theory of $\mathrm{OM}$ will be more than an accumulation of supporting theories derived elsewhere, but can utilize existing theories in its foundational base. An example might clarify this. Robertson, Ulrich, and Filerman (1991) note that current computer-assisted design (CAD) systems are not as powerful as they might be because they were originally designed to support the drafting function. Hence, the system primitives in a CAD system are arcs and lines. Consider, however, a system designed to support a sheet metal-forming processes. Such a system would have "bending" and "punching," for example, as its system primitives, and the production process and sequence would evolve simultaneously with designing the part. One can think of such a system as a "higher level" language, 
one for which a "punch" implies not only a circular hole but an attendant mechanical process. What are the system primitives with which we design and analyze an operation? Can these simultaneously imply mechanical, human resource and financial consequences? A theory of oM can and should leverage the theories available in supporting disciplines, but should also make their interrelationships known in a manner uniquely suited to $\mathrm{OM}$ practice.

For us to teach effectively and remain viable in research institutions, it is imperative that such a theory develop. This will be very difficult, indeed. Rational people might argue against this direction for our field. Their argument would be that the totality of oM practice is irreducible to theory and that as academics we are better off adding to the evolving theory in some supporting discipline (OR, for example, or sociology) and then interpreting that theory in the oM context. I do not think, however, that this is sufficient to sustain oM as an independent field in a research institution. I believe that we must wrestle with what $\mathrm{OM}$ is and what theoretical underpinnings we can place beneath the holistic exercise. I will now review the current status of om theory, the changing landscape, and a proposal for the future.

\section{Current Status, Our OR Heritage and the Changing Landscape}

\section{A. Current Status}

Operations management, like management in general, is a practice that currently rests on supporting disciplines, each of which rests on its own theoretical foundations. For OM to have a place in academia it must have a theory that is uniquely associated with oM and uniquely delivered in om courses. The strongest current contenders to be part of this theory are the theories of optimization and queues that have been derived over many years in the field of operations research.

In particular, the theories of mathematical programming and queues come closest to being theoretical constructs uniquely associated with $\mathrm{OM}$. In business schools, these subjects are likely to be presented only in OM courses (there might be some optimization in economics courses). These subjects are tight, logical constructions that can trace their sequence of "why's" back to basic mathematical axioms. Mathematical programming informs practice with such statements as, "Under these explicit assumptions a profit maximizing manager would choose this particular input set and be willing to pay a specified number of dollars for an extra unit of capacity, and this is true because (we then articulate the logic behind duality and shadow prices). Further, this solution is robust to changes in input prices, e.g., up to these specific limits." The many applications of linear programming in industrial practice testify to its relevance.

Queues describe the physical behavior of material flows in a random environment, and as such inform practice with such statements as, "Excess capacity on average is necessary in a variable environment because (here we articulate the logic of idleness due to starvation and its consequences for long-run congestion and delay in the system). Further, the deleterious effects of congestion increase dramatically and nonlinearly with utilization. So, an extra increment of capacity is worth much more at high utilizations than low ones." Queues, in particular, provide insight into the consequences of variability. Queuing network models have found voice in telecommunications practice, but in general have not had the impact that linear programming has. It can be argued that queuing intuition is underapplied in practice. Most managers (and students) can intuitively understand the concept of average, or mean, behaviors. Many have no internalized sense of what variability is or what it does to processing networks. Queues can be a vehicle to this insight. There are important problems facing operations managers (e.g., the costs of product proliferation on manufacturing resources or the challenges of attaining higher equipment utilizations in job shops) that are informed by queuing theory. 
The major results derived from these theories are robust to changes in venue, and the assumptions are not so restrictive that they preclude reasonable representations of real systems. There is admittedly a fair amount of restrictive and less powerful research in these areas as well, but this should not detract from the contributions of the best works. These are very powerful theories and have great (and often realized) applied potential, and we would gut our field by ignoring their cultivation and use. However, they are not theories about $\mathrm{OM}$ and are not sufficient to sustain our field in business schools. These $O R$ techniques are not sufficient to address all the problems of the day and hence to carry oM as a field. They cannot be jettisoned, but they are not enough. To understand why, consider what is happening in the management environment and what our OR history prepares us to do.

\section{B. The Changing Landscape}

I will refer to the "task environment" in which a firm operates as the spectrum of challenges that face a firm that is striving to compete and prosper. I believe that the task environment for many firms is becoming more volatile. This belief is based on the accelerating pace of technological change, rising consumer expectations that increase the level of competition along a variety of dimensions (price, quality and speed), and the presence of an increasing number of competitors as more than a few national economies vie for premier status.

There is broad support in the theory of organizations and in supporting empirical research, that more volatile task environments will prompt firms to organize and manage themselves differently (cf. March and Simon 1958, Burns and Stalker 1961, Woodward 1965, Thompson 1967, Litterer 1969, Galbraith 1973). Specifically, in a more volatile task environment one will expect to see the following: (1) An increase in the presence of creative problem solving, rather than the execution of pre-set programs and algorithms, and (2) More decentralized decision-making, pushing the authority to make decisions down the management hierarchy.

If we accept these relationships, then we can expect the following to rise in importance in the practice of oM: (1) investments in human resources, which are the engine for creative problem solving, and (2) decentralized means for coordinating divided labor.

That part of our OM heritage that derives from oR does not set us up gracefully to deal with these changes. First, the standard oR challenge is posed in terms of a mathematical model with known parameters. Without these inputs, optimization is impossible (I am skirting the issue of adaptive control, but the universe is still closed in these constructs, as it must be to be mathematically tractable. There is simply no room for the unimaginable ). There is unlikely to be a strict calculus of creativity, and yet the theory we develop to support OM must help us manage this phenomenon. We will likely have to embrace and incorporate some important, nonquantifiable aspects of human nature.

Also, the typical or optimization problem is fundamentally centralized in nature. That is, the archetypical oR challenge is to seek a solution to the problem of maximizing some function over a feasible set. Once the optimal actions are known, it is implicit that they should be implemented. That is, the thinking about what should be done is delegated to a central processor, and people simply follow the prescriptions of the algorithm. This is a centralized vision of a firm. This vision can trace its roots to the rationalist philosophies of the Enlightenment, and finds its current voice in MRP-X systems (in which an entire firm is centrally coordinated) or a lights-out factory controlled by a central algorithm. These systems are appropriate in stable task environments, but to manage in a more volatile environment, we will have to embrace effective decentralized coordination systems. A corollary observation is that the mathematical aspects of oM theory might increasingly embrace multiperson models (e.g., group decision-making and game theory), which had an early presence in oR but currently occupies a marginal position in our field. 
Decentralized structures also imply more lateral rather than vertical interactions. That is, oM will have to broaden its view to include the agendas of other functions in the firm. Indeed $\mathrm{OM}$, situated as it is at the technological core of the firm (see Figure 1), is ideally positioned in the business school community to develop cross-functional sympathies. The boundary-spanning activities of marketing, purchasing, finance and human resources (HR) interface between OM and the external product, factor, capital and labor markets, respectively. OM must manage these interfaces successfully to achieve its value-producing mission.

Can om develop a self-consistent world view that is inclusive of these needs? I think the answer is yes, and I will propose a framework for thinking about this in what follows. My proposal is broad enough to inform oM problems of modern complexity, yet is constrained enough to have some hope of being filled out with academic rigor. In the next section I present and defend this framework.

\section{Integrated Operations}

Figure 2 shows the intellectual foundations for an integrated view of om. The sides of the pyramid are rooted in fundamental disciplines that become more applied as we move toward the apex. I intend to fill in this pyramid more completely below. I begin with the foundational disciplines and their applied sciences.

\section{A. Foundational Disciplines and Applied Sciences}

Here I present a very brief description of the foundational disciplines on which I believe a synthesis, an integrated om theory, can be based. These are physics, social psychology and philosophy.

Physics attends to the physical feasibility of, and anticipation of actions and reactions for, interacting physical objects. It can be argued that engineering is the applied use of physical conservation laws. Our notions of technical process design have their roots in physics and engineering.

Social psychology attends to the anticipation of actions and reactions of human resources. Organizational behavior can be thought of as applied social psychology. Our notions of social system design have their roots in these disciplines.

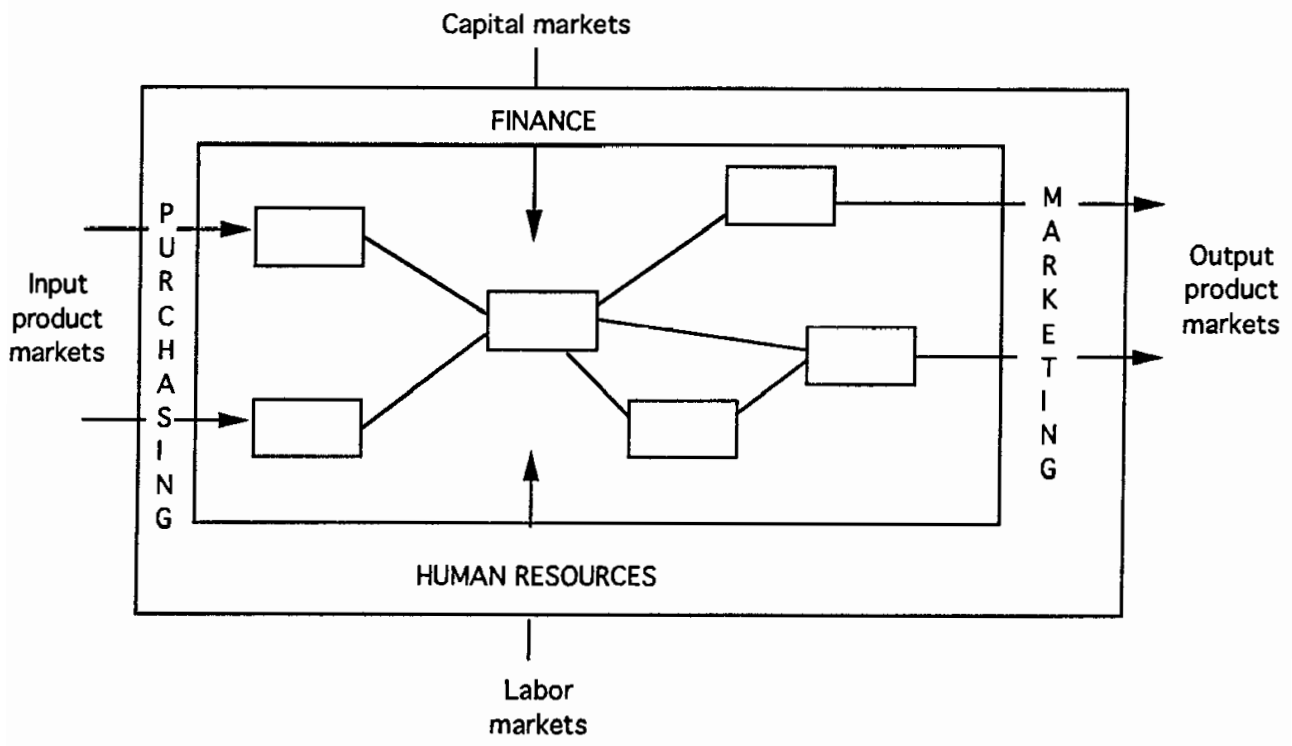

FIGURE 1. Operations Management Resides at the Technological Core of the Firm. 


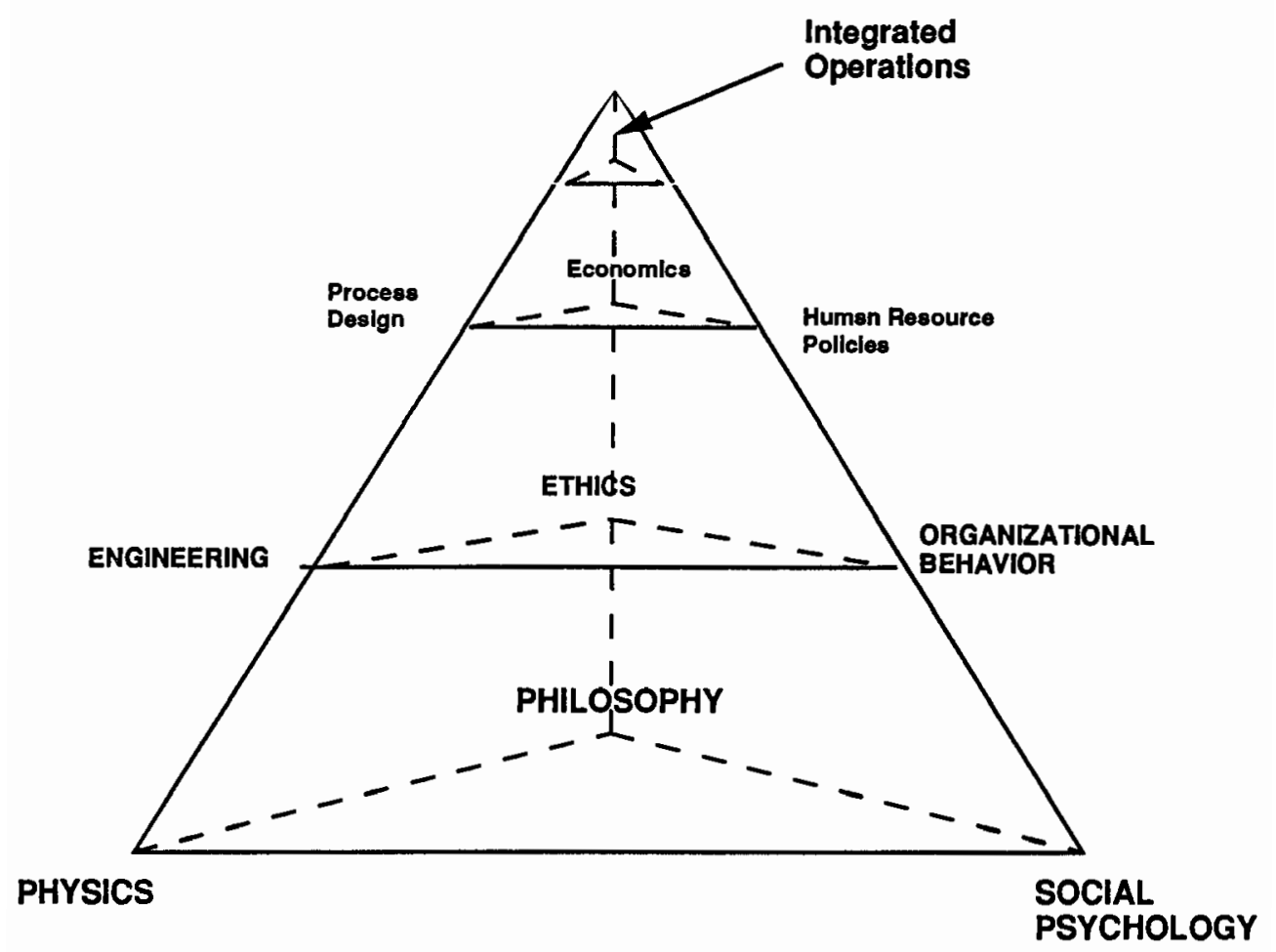

FIGURE 2. The Foundational Disciplines of Integrated Operations.

Philosophy provides an objective function: Why are we doing what we are doing? We all need to carefully consider what is on the left-hand side of our life equation. Ethics can be considered applied philosophy, attending to the achievement of a better society and each individual's obligations relative to that goal. Having defined OM as the selection and management of transformation processes to create value for society, we must root our discipline in some understanding of how our actions and prescriptions relate to a productive, fair and just social order. As will be seen below, I am not proposing that we tell people how to behave to be a moral person. Rather, I am proposing the construction of a theory that informs practice, contingent on the acceptance of (perhaps user-specific) behavioral norms that are ethically credible, and broader than profit maximization.

Each of these foundational disciplines would take a lifetime to master. To be practical in its intended scope, the oM professional needs to distill from these foundational disciplines those concepts that are required in the network of concepts that we need to properly inform the practice of oM. I suggest such a distillation below.

\section{B. Applied Disciplines and Basic Tools}

I believe that an integrated theory of OM will rest upon some basic tools from the foundational disciplines. The following is my proposed list of tools and the rationale for choosing them. The reader can easily associate these tools with important oM concepts. Figure 3 adds these concepts to the basic pyramid.

1. AlONG THE PHYSICS/ENGINEERING LEG. The fundamental engineering concepts that we need to embrace to support technical process design in OM are the notions of conservation of mass, the load being placed on a system relative to its capacity and the effects of variability in that load.

Conservation of Mass. This obvious concept finds voice in things as transparent as an MRP parts explosion, but is also important in computing long-run utilization profiles in 


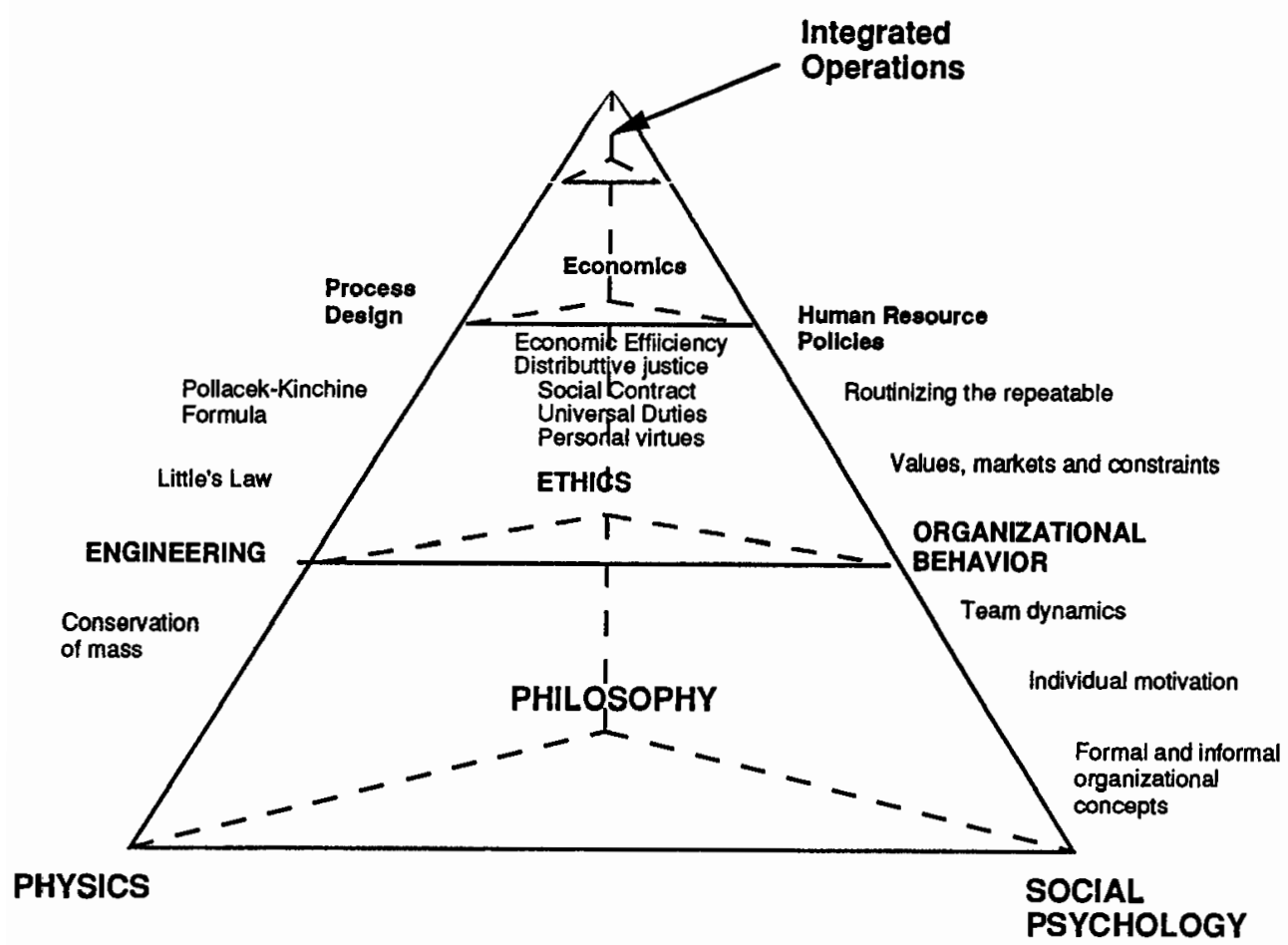

FIGURE 3. Basic Tools in Integrated Operations.

processing networks. What goes in must come out in the long run. A lot of mileage can be had from this simple concept. A utilization profile and bottleneck analysis are important first steps in technical process design and improvement initiatives.

Relationships Among Averages, Little's Law. Little's Law (inventory = throughput rate multiplied by residence time) derives from physical conservation laws and explains the link between inventory and time. Indeed, Stalk and Hout's (1990) recommendations for time-based competition are remarkably similar to initiatives undertaken in inventory reduction (just-in-time) efforts. Little's Law, derivable from first principles, tells us why.

The Pollacek-Kinchine Formula and the Effects of Variability. As I noted above, most students and managers seem to have an intuitive notion of the average or mean of a variable quantity. Many do not, however, have an intuition about variances about that mean, and its consequences for processing networks. The Pollacek-Kinchine (PK, cf. Heyman and Sobel 1984 and Figure 4) formula nicely captures some important tradeoffs. Specifically, inventory, capacity and (lowering) variability are substitutes in that more of one allows you to decrease the others. If you have a lot of excess capacity, you can satisfy very random demand with little inventory or delay. If you do not have capacity, you will either have to hold a lot of inventory or let demand go wanting. If you can smooth the demand placed on a facility, you can get by with less inventory and capacity. Any om practitioner will recognize these tradeoffs, which can be nicely captured in the compact PK formula. I often present these concepts in terms of the "OM triangle"' shown in Figure 4. If one associates forecast error (lack of information regarding demand) with variability, then it is easy to extend these notions to capacity, inventory and information being substitutes in providing good customer service. The PK formula is derivable from physical laws and assumptions.

These fundamental physical relationships have been noted and amplified by others in the om community. The Factory Physics text by Spearman and Hopp (1995) guides an effective om course from this perspective. Schwarz (1996) proposes an analytical frame- 


$$
\begin{aligned}
& \text { Inventory }=\mathrm{K} \times \frac{\rho}{1-\rho} \times \text { Var } \\
& \mathrm{K}=\text { constant } \\
& \text { Irıventory }=\text { long-run average inventory } \\
& \rho=\text { long-run utilization }=\frac{\text { demand rate }}{\text { capacity }} \\
& \operatorname{Var}=\text { variability }
\end{aligned}
$$

\section{The Pollacek-Kinchine formula}

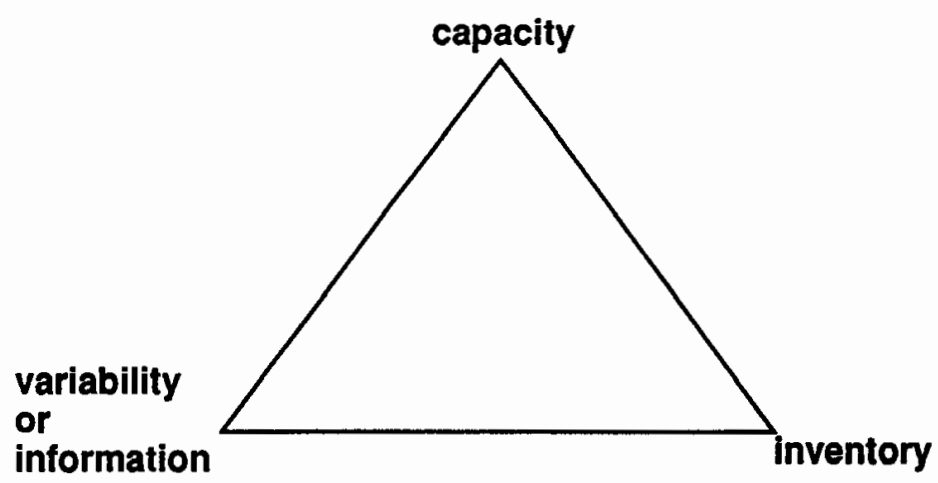

FIGURE 4. Capacity, Inventory and Variability (Information) Are Substitutes in Providing Customer Service.

work that recognizes the relationship between information, variability and buffers. I believe that there is common ground here that we should clarify and embrace. I have found this to be a powerful and robust way to view the technical oM alternatives in serving customers.

2. AlONG THE SOCIAL PSYCHOLOGY/ORGANIZATIONAL BEHAVIOR LEG. Human dynamics are much less predictable than physical dynamics, and the logical constructions on which organizational theories are based are not as deep as those in the physical sciences. Human psychology obeys no conservation laws that we know of, and the predictive power of the social disciplines cannot currently match that of physics and engineering. Nevertheless, there are conceptual foundations that derive from these disciplines that have explanatory power and can help intellectually frame the social issues in $\mathrm{OM}$.

The fundamental challenge of management is the coordination of diverse resources toward some focused objective. Coordination, or lack of it, pervades any managerial issue. The basic tactic by which firms attend to their tasks is the division of labor and the subsequent reintegration (coordination) of that divided labor. We need to know, then, how to divide the labor and by which mechanisms can we reintegrate the divided whole? The basic tools that we need include both formal and informal organizational concepts.

a. How to Divide the Labor? The "perfect" division of labor requires no coordination; that is, the individual activities are autonomous and can proceed in parallel. This minimizes managerial (coordinative) overhead. Using this as a point of departure, one can strive to divide the labor such that the strongly interdependent activities are in the same "'group." This should minimize the coordination effort required to integrate the activities 
of each group in the divided whole. This concept underlies many reorganizations and reengineering activities. For example, functional organizations concentrate on functional depth. As customer service and throughput time become more important, one will want to alter the division of labor and reorganize along product (or product group) lines. Essentially, you want to keep the important interfaces within and not between groups. This basic concept finds voice in OM in modular designs such as cellular manufacturing, team formation and product architectures.

b. How to Reintegrate Divided Labor? Seldom will a complex of tasks be divisible into completely autonomous modules, so that some reintegration mechanism is necessary. Three fundamental means for reintegrating divided labor appear (albeit with different labels) in a variety of literatures. These are constraints, markets and values. These tactics are briefly described below. Figure 5 presents some support in the literature for the centrality of these concepts in the study of the coordination of resources.

Constraint-based integration refers to the classical top-down form of organization, which some authors trace to eighteenth century military models. The archetype is a perfect bureaucracy. The term "constraint" is appropriate because the basic model denies discretion and freedom of motion to subordinates; they are told what to do. Constraint-based management is implicit in many OR models, which presume to compute optimal behaviors and then 'tell"' people what to do. MRP systems, quality function deployment, management by objective, and other top-down, hierarchical coordination methods are fundamentally constraint-based in character.

In a market-based system, people are allowed discretion but are appraised of the costs and benefits of alternative actions or outcomes. People retain their freedom of action, but there is a profit/loss type of computation that attends each of the alternative actions that can be taken and by which performance is appraised. The archetype for market-based integration is a free-market economy. Business examples include piece-rates on the shop floor, incentive contracts for managers, and multidivisional firms with transfer prices between divisions and in which each division is judged based on divisional ROA.

Values-based integration seeks to generate a shared sense of values within the group to be managed. If successful, people will know instinctively what to do without explicit

\begin{tabular}{|c|c|c|c|}
\hline Markets & Constraints & Values & Literature \\
\hline Markets & Hierarchies & & Transactions Economics1 \\
\hline Markets & Bureaucracies & Clans & Organizational cultures ${ }^{2}$ \\
\hline \multirow[t]{2}{*}{ Market } & $\begin{array}{l}\text { Technical or } \\
\text { scientific }\end{array}$ & $\begin{array}{r}\text { Commitment or } \\
\text { mutuality }\end{array}$ & Human Resource Management ${ }^{3}$ \\
\hline & Mechanistic & Organic & Organizational structures 4 \\
\hline $\begin{array}{l}\text { Price-based } \\
\text { decomposition }\end{array}$ & $\begin{array}{l}\text { Constraint-based } \\
\text { decomposition }\end{array}$ & & $\begin{array}{l}\text { Operations Research/ } \\
\text { Management Science } 5\end{array}$ \\
\hline
\end{tabular}

1) cf Wiliamson, O. Markets and Hierarchies: Analysis and Antitrust Implications. Free Press, 1975.

2) cf Ouchi, W. Markets, Bureaucracies and Clans, Administrative Science Quarterly 25, 1980, 129-141.

3) cf Walton, R. and P. Lawrence (eds). Human Resource Management Trends and Challenges, Harvard Business School Press, 1985.

4) cf Burns, T. and G. Stalker. The Management of Innovation. Tavistock Publications, London, UK 1961.

5) cf Bazaraa, M. and J. Jarvis. Linear Programming and Network Flows, John Wiley and Sons, N.Y. 1977.

FIgURE 5. Literature Support for Framework Using Markets, Constraints and Values. 
constraints or rewards. The archetype is a religious sect, wherein each person believes in the organizational goals and objectives and is willing to contribute toward those goals without promise of reward or sanction. Values were claimed by William Ouchi (1981) to be the distinguishing feature of Japanese competitiveness. Mission statements and team building efforts are, in part, attempts to craft a sense of shared values within firms.

Each of these forms of integration has its own strengths and weaknesses, which I will not take time to articulate here. Constraint-based management is associated with centralized, "mechanistic" management, whereas values and markets (by allowing subordinates more discretion) are more decentralized, or "organic." Real firms will always use a combination of these three integration techniques, but the relative mix might differ from one context to another. I can speculate as to some of the contingencies on which the appropriate mix will depend. These are the volatility in the task environment, the level in the decision hierarchy of the firm and the maturity of the firm in its industry. In particular, for more volatile task environments, newer firms and/or higher level decisions the mix of integration mechanisms will be weighted toward organic (markets and values) techniques. Likewise, in stable task environments, mature firms or lower level decisions constraints, e.g., in the form of rigid work rules and procedures, will be more apparent (see Section c below). These claims rest on existing organizations and control systems research, but more needs to be done. If these claims are correct, then as the task environment destabilizes, we will want to look toward more market- and values-based management techniques in managing firms. This will have consequences for how we organize the social systems of production.

c. Routinizing the Repeatable. If some task is to be repeated many times, it makes sense to find out the best way to perform the task and then require its execution according to that "best practice." This means that in stable task environments, stable work routines and policies will be generated over time, and this is efficient. This derives from March and Simon's (1958) model of organizational learning. The consequences for this are that one will want to consider the relationship between efficiency and discretion allowed workers in a stable environment. It is no coincidence that social scientists find more constrained actions and mechanistic control systems in mature industries with stable technologies. This also supports the choice of task environment as a critical contingency in choosing the appropriate mix of integration methods.

d. The Informal Organization. With the exception of values-based techniques, the above concepts pay little attention to the uniquely human character of the individuals who populate an organization. The market-based literature, dominated by economics and principal-agent research, typically employs a simplistic model of human motivation (e.g., profit maximization and effort aversion). This is an important start, but in reality people bring to firms a more idiosyncratic and complex bundle of needs, phobias and dreams. Litterer (1969) notes that a failure to account for individual human emotions in a formal organizational design misses the important point that real people must live within the organization while its objectives are being pursued.

Richer notions of human behavior are needed to explain the success of small teams and failure of large ones, the success of some motivational techniques and failure of others. The team concept is central to many modern oM initiatives, and an integrated theory of OM will have to explain the nature or behavior of team phenomena. I do not yet know what fundamental tools we will use to get started in this complicated arena, but it is currently an active area of research (cf. Tuckman 1965 for a traditional model of team behavior, and Hackman, Brousseau, and Weiss 1976, Hackman and Oldham 1976, and Gersick 1988, 1991 for more recent advances).

3. ALONG THE PHILOSOPHY AND ETHICS LEG. There is currently much more attention paid in modern education to the right-hand side (what levers does one pull?) than the 
left-hand side (how do we measure success?) of the performance equation. In most business courses the objective, usually unquestioned, is to maximize shareholders' wealth (or firm value). There are two reasons to reexamine this objective in greater detail. First, as a matter of principle we want to carefully reexamine our theoretical foundations before proceeding. Second, the assumptions on which the profit motive is based can be challenged in significant ways and a robust theory requires that we attend to these challenges.

The rationale behind the classical financial objective derives from the theory of free markets: everybody pursuing this goal in a perfect market economy will, in aggregate, provide the most value to society at minimal cost via Adam Smith's invisible hand. Yet, markets are always imperfect, leaving scope for maximizing individual gain at the expense of society at large. From insider trading to environmental pollution and worker safety issues, market failures of one sort or another can allow firms to maximize profits at society's expense. This does not abrogate free-market theory, but it does imply that theory is not sufficient to fully inform practice.

Also, distributional considerations and issues of faimess and justice are not addressed by the classical objective. Yet, no effective plant manager would ignore how the distribution of rewards will be perceived by his or her employees. Distributional issues and issues of fairness often dominate real (as opposed to theoretical) policy debates. An appropriate incentive structure for team-based production would have to recognize not just profit maximization as a person's objective, but also feelings of fairness and justice. Laying off workers while the chief executive officer makes tens of millions of dollars in stock options might be justifiable from an efficiency perspective, but it might also wreak havoc with morale (and by extension, performance). This adverse reaction on the part of many workers and objective observers stems from an implicit sense that distributional issues have a role in defining a "better" society.

Since we have defined operations management as the selection and management of the transformation processes that create value for society, we will want to carefully examine what sorts of actions serve that value-creating goal. Personal virtues, religious injunctions, the social contract of Thomas Hobbes, the Universal Duties of Immanual Kant, notions of individual rights, economic efficiency and utilitarianism and the notions of distributive justice of John Rawls are all tools that one can use to think through the ethical dimensions of a managerial problem. Useful summaries of these complex theories are now becoming available from ethicists (cf. Hosmer 1994, Velasquez 1992, Beauchamp and Bowie 1988 and references therein ), and these are sufficient to generate a set of potential performance criteria that is more robust than maximizing shareholder wealth. Especially if, as I suspect, human resource issues become increasingly important as the environment destabilizes, the profound ethical content in the nature of a firm's obligations toward its employees (or lack of same) must be thought through. This is not, again, an attempt to prescribe the "right" code of ethics, but instead to suggest that we will want to inform practice with alternative objectives (or combinations of objectives) that are more general than the traditional one.

From a research perspective, profit maximization dominates the objective functions in the current literature and will likely remain dominant. I do not know what the consequences would be of extending that function to include distributional and other issues (but see, for example, Boiney 1995 for a discussion of what an extended objective might look like). There are alternative notions of how one can contribute toward a "better and more just"' society that are amenable to careful analysis in an oM-relevant context. For example, Rawls' notion of distributive justice might be amenable to game-theoretical behavioral models. More thought is required here. I am convinced, however, that profit maximization cannot be blindly accepted as the objective of OM in all circumstances. We need to at minimum address the potential multidimensionality of the objectives of our field. 
Likewise, business leaders should not ignore the philosophical issues presented by opportunities that derive from market failures. We cannot tell our students, who are future business leaders, what to do, that being between them and their God. We can and should, however, present for their consideration a more general set of alternative ethical principles than is currently the case in business schools. In constructing this set, we can use as points of departure the conceptual frameworks that careful thinkers have proposed for navigating these complex waters. Likewise, our normative om theory should be capable of using as its objective an enlarged set of criteria.

\section{Current Status of Work Bridging the Foundational Disciplines in Integrated Operations}

Looking further up the sides of the integrated om pyramid, we see the application of engineering and physical tools to process performance models and technical process design and the application of organizational behavior tools to job design and HR policy. The application of ethical reasoning to define our objective has until now been dominated by economic efficiency (utilitarian) considerations. An integrated oM course will use a combination of these tools and concepts to address the full richness and complexity of real managerial challenges. Several subliteratures already exist at the interfaces of these disciplines, as shown in Figure 6. These are described below.

\section{A. The Process Engineering/Process Economics interface: Operations Research}

Operations research optimization models lie at the interface of technical design and economics. OR models invariably use one or several engineering models of physical behavior to describe the dynamics of the system. In optimization models, profits (or some direct measure that is presumed to correlate with profits) is used as the left-hand-side objective function, and the optimal (most profitable) actions are computed. This subli-

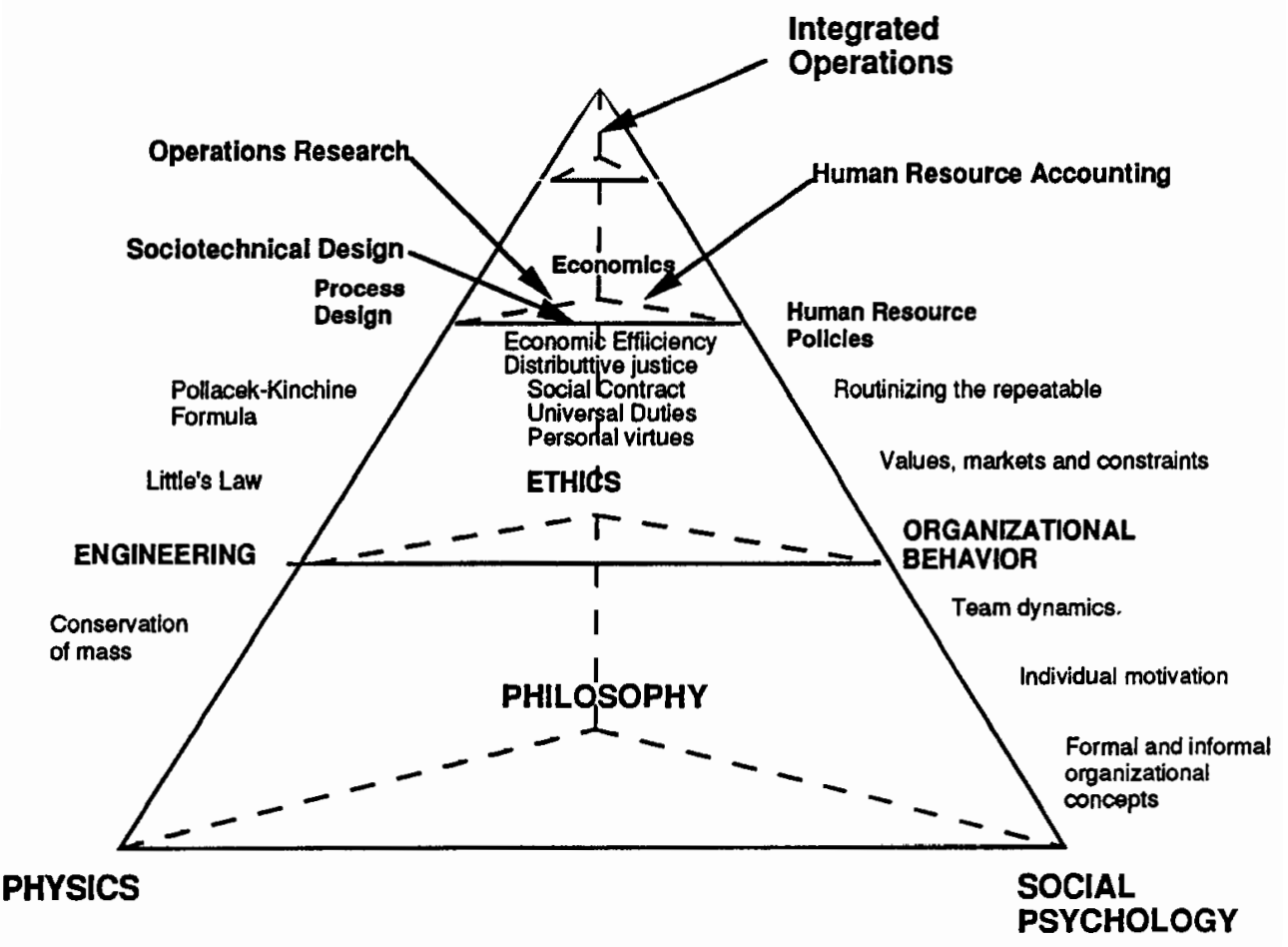

Figure 6. Current Research at the Disciplinary Interfaces. 
terature has yielded some powerful conceptual and algorithmic devices that should be a part of any holistic om education. These devices include the following:

1. Linear PROGRamming. Clarity in the construction of mental models of business processes, optimizing subject to constraints and the notion of opportunity costs or shadow prices should be fundamental parts of the culture of OM education. It is ironic that linear programs (LPs) are being squeezed out of OM curricula across the country at the same time that their use is becoming easier because of user-friendly spreadsheet interfaces. The fault lies with us, in failing to make these tools come alive to students worrying about running a business. Students who will work to understand the capital asset pricing model do not exert effort to understand a linear program, because he or she does not see the relevance of the latter as clearly as the former. LPs are very powerful models from both an applied and an intuitive perspective, and they have a rich theory associated with them. They find productive use in industry and should be maintained in our curricula. The passing of LPS from OM courses is due not to lack of relevance or potential for insights, but rather to our failure to make the power of these models obvious to students.

2. ECONOMICS OF VARIABILITY. The economic treatment of variability essentially places a value on variance. Examples include safety stock models (hedging upside and downside risk) and the economics of congestion (delivery delays and inventory) in processing networks. Intuitive notions of variability and the economic consequences of managing around it are important topics that are addressed by the oR literature and are currently included and should remain in most om courses. The tradeoffs between variability, inventory and capacity have already been mentioned above.

Currently, oR provides the deepest theory that students are likely to get uniquely in an OM course and to associate uniquely with OM. Our OR heritage cannot be jettisoned, it is our most persuasive current claim to academic standing. However, current OR models do not capture the richness of the oM context, and we will want to begin in our discipline the long but exciting process of drawing more complete theoretical linkages between the foundational disciplines underpinning $\mathrm{OM}$.

\section{B. The Process/HR Interface: Sociotechnical Design}

The term " sociotechnical" refers to the simultaneous consideration of the social system and technical system when designing an organization. The field of sociotechnical design began with the famous long-wall mining studies of Trist and Bamforth (1951), who describe the social disruptions that attended a shift from small autonomous work groups to a more routinized, mass production approach to coal mining. The new system was technologically rational but socially undesirable. An improved system of coal mining would compromise a little on technological rationality to achieve gains in social acceptance, which in the end will be more productive. The concept of sociotechnical design, in theory, should not give precedence to either the technological or social system, but instead try to jointly optimize the two. Current empirical studies (cf. MacDuffie and Krafcik 1992) have verified the superiority of this joint perspective in process design.

However, the literature on sociotechnical design (cf. Pasmore 1988) tends to be dominated by an implicit assumption that autonomous work groups are good, perhaps due to Trist and Bamforth's (1951) early observations. It is not true that autonomous work teams will always be better. In fact, relying on the learning model of March and Simon (1958) mentioned above, one can expect a removal of discretion from workers over time in stable task environments. This, and some notable failures of experimental "sociotechnical" work systems in Scandinavia, have not helped the sociotechnical movement.

However, while one can legitimately be skeptical of the autonomous work team as an axiomatic benefit, we cannot on this basis dismiss the important challenge that the sociotechnical concept poses for us. Humans are important inputs to production systems, and 
in many firms the tacit knowledge resident in the workforce is of greater value than documented work rules and procedures. It is clear that the design of the social system of production warrants attention. There are also important human resource issues that will attend process improvements in stable environments. What do you do with "empowered" workers who improve a process to $99 \%$ of theoretical capacity? How do worker job descriptions, discretion and autonomy change over time, and how is this process managed to the benefit of all parties? We still need to wrestle with these issues to offer a holistic view of oM. The philosophical idea behind the sociotechnical literature, that one cannot ignore the social system in process design, remains valid and worthy of more careful study.

\section{The HR/Economics Interface: Human Resource Accounting}

Touting people as our "greatest resource"' is a common claim made by modern businesses. Indeed, in knowledge-intensive industries human assets can represent a significant competitive advantage. In simplistic terms, machines are proficient at the efficient repetition of well-structured tasks, and humans are proficient at learning and innovation. In a rapidly changing competitive landscape, then, workers will gain in strategic importance relative to machines. Yet, managerial practice has not responded to this reality. The costs and benefits of investments in capital assets will be computed in detail, yet investments in human assets are approved or disapproved on an ad hoc basis.

The function most closely related to the performance of human assets, and the associated areas of job satisfaction, turnover, and human development is the human resources group. The relationship of the HR function to the firm's overall agenda is complicated by the qualitative nature of people, which does not join seamlessly with the quantitative counting of dollars and cents. Many problems with valuing human assets are attributable to the inability to quantify the costs and benefits of HR alternatives. The controller can rapidly compute the payroll savings to be had from a temporary layoff and predict the improved bottom line and ROE. The human resource manager may be fearful of the turnover and morale effects of a layoff and the attendant loss of tacit knowledge, but can offer only uncertain, qualitative observations unsupported by data. The controller will often carry the day.

In one sense, the subtlety and complexity of the human animal precludes precise laws of behavior or models of cause and effect. However, in the absence of an ability to compute the costs and benefits of work force initiatives in a common unit of exchange (dollars), one cannot systematically compare these initiatives with business alternatives, leaving only opinion and faith to guide us. Sometimes this is sufficient, often it is not.

Human resource accounting (HRA; cf. Flamholtz 1985, Flamholtz and Coff 1994) is a subfield of accounting that generated considerable academic interest in the 1970s, but has declined in popularity since. The basic idea was to keep track of human assets (based on historical investment minus depreciation) much like capital assets. This would allow a firm to compute such things as a return on human assets and help rationalize investments in those assets. The original proposal included reporting these assets on the firm's financial statements. The author knows of only one firm that adopted such a system (the R. G. Barry Corporation, which makes Dearfoams and other soft apparel; cf. Woodruff 1970). However, this company no longer uses an HRA system, and indeed recent phone calls reveal no corporate memory of ever having used one.

Flamholtz attributes the decline of HRA to the riskiness and uncertainty of the effort, and (in academic circles) to the fact that the easy research has been done and only very complex problems remain. Other critics attribute its decline to more fundamental flaws. Dittman, Juris, and Revsine (1976) pose a strong economics-based counter-argument, claiming that an essential difference between humans and machines (humans can leave and take other jobs) means that wages must rise to capture learning benefits, so that no 
asset is created as a result of investments in people. Dittman also describes the important distinction between firm-specific training (for which the market value of the recipient will not rise) and general training (for which it will).

We can conclude from this that the early HRA systems are probably flawed in their techniques for capturing the value of human assets and the expected return for investing in those assets. However, the important question of how to do this properly remains on the table and increases with importance as we enter more volatile oM task environments. Absent some rational system for bringing human resource alternatives into the mainstream planning and control processes of the firm, oM managers will have no support for important people versus technology capital-budgeting decisions. An integrated view of om must at minimum wrestle with this issue.

\section{Teaching as the Vehicle for Change}

Since the Ford and Carnegie Foundation reports of the 1950s, business education has gained in academic respectability by being rooted in more rigorous academic disciplines. The maturing of business research paradigms means that the standards for publication are now very strict and must in most cases conform to those of one contributing discipline or another. Articles such as this one, for example, which do not attempt to reach academic depth in any one area but instead explore the relationships between areas, are notoriously difficult to publish outside a forum that is purposely dedicated to the broader view. This avoidance is a natural reaction from editors dedicated to upholding academic standards, and since there really are no such standards for integrative articles, a risk-averse editor will most often choose to reject. Unless I can propose a standard for integrative articles, which I currently cannot, short of qualitative statements such as "thoughtful" and "careful,"' I will choose to live with the current system.

The consequences of this are as follows. To publish an academic article some manner of proof or disproof is needed. However, prior to proving or disproving anything, we need to frame the questions. Question framing is not the stuff of academic journal publications. If one is to propose and start down the path of asking and answering a new set of questions, one will have to proceed at least on two fronts. The first is a holistic framing of what is to be done and why, and the second contains narrower, more rigorous investigations that begin the process of carefully building a new literature. The latter we are trained to do. The former can benefit from the sort of organization of material that one naturally brings to a course design. Teaching can precede research in these integrative arenas.

In the classroom we have an obligation to do our level best to provide students with practical truths that will benefit them as managers. Challenging ourselves to define these, and support them, is the most useful catalyst I have found for intellectually framing new perspectives on ом. In research we must report only that which is proven true, but the collection of these proven results always falls short of the needs of complex business activities. In the classroom, we have the obligation to give our students more, to share our judgment about what we believe to be true and what the consequences of those beliefs are. As long as we do this with full disclosure (which material being presented in class is well rooted in research and which is more speculative), we are doing the students a service. Indeed, I have found great value in inviting students to speculate with me on some of the more challenging issues. In parallel with this teaching effort, we should begin the long road of underpinning our judgment with rigorous investigation.

\section{A. Getting From Here to There: Maintaining OR in the Curriculum}

In the near term, we should maintain the presence of LPs and queues in our coursework, but we should acknowledge their incompleteness as well as the creative, open-ended nature of management by using them as just one set of tools useful in a richer context. 
For example, we should not ask students to "find the optimal product mix" as much as we should present students with a rich management problem in which the standard techniques offer an important, but incomplete perspective on the solution. Examples include the following:

1. A case in which students reorganize a shop floor into business units, concerning themselves with the customer requirements (e.g., speed, cost and customization) of different products and the internal organization (workforce, incentives and career paths) as well as material flows and utilization profiles.

2. An exercise in which students place production in an international network, considering tariffs, exchange rates, infrastructure and political and labor volatility as well as material flows through the production network.

3. A capital-budgeting exercise for investments in technology in which issues of volatile market demands in both volume and mix, a technology strategy that is internally consistent with all functions in the firm and the integration of new equipment with the current human and material processes are considered simultaneously.

Competitions among student groups are particularly effective in motivating the use of support tools. Such cases and competitions would be multidimensional, but could not be done well without the attention to physical flow detail that is our current strength. They would allow the students to develop the skill to use our most powerful tools in practice. Such cases and exercises are currently being generated and used, and I am sure that we will hear more about them over time.

As our theoretical base expands, we can introduce more of our evolving vision of oM into our courses. In the interim, we can leverage the concepts and theories derived elsewhere ( $\mathrm{OB}$, finance and marketing) to place $\mathrm{OM}$ in the greater context of the firm. OM also has the opportunity to become the most cross-functional group in the school and hence the capstone discipline. It is naturally and ideally situated at the core of the firm. It is what the firm does to create value. This message should be clearly delivered.

\section{B. The Role of Senior Faculty}

Senior faculty must take the lead in initiating changes in our field. The political realities of the tenure process make junior faculty, for better or worse, risk averse. Also, they in general lack the experience needed to craft a compelling overall strategy for the field. Rather, they are best deployed helping us nail down some specific parts of the whole. They can, however, and probably should be encouraged to teach integrative electives so that they can begin to see themselves as part of a greater context. In summary, senior faculty must accept a dual responsibility to the health of our discipline and to the careers of our charges.

\section{Summary and Conclusions}

This paper is primarily targeted at professors of oM in research institutions. I have argued that the theory, practice and teaching of $\mathrm{OM}$ are interdependent, each feeding the other. I have also argued that to remain viable as part of the research establishment we must construct a theory that is uniquely associated (that is, emphasized in no other classroom in the business school) with OM. Currently, our OR heritage provides such a theory, but the technical dominance of that paradigm renders it too narrow to address, in isolation, the richer tapestry of problems that we face. From this, I conclude that we should expand our theoretical base to include social and philosophical issues.

$\mathrm{OM}$, which resides at the technological core of the firm, is ideally situated to take on this expansive, inherently cross-disciplinary role. Yet, cross-disciplinary work in and of itself does not constitute a theory, and a claim to be cross-disciplinary does not secure one a place at the academic table. Instead, I propose that we take the first steps to build 
a larger, more encompassing theory of OM. I have suggested what the foundations of such a theory might be and have reviewed some of the existing work at the interfaces of the foundational disciplines. This work is incomplete, and in some cases not currently active. Herein lies the opportunity.

Networking these fundamentals into a cohesive whole is the task ahead of us. I find the challenge exciting, if daunting. Historically, efforts to construct a "unified field theory" of management have not been successful, a fact that should temper our enthusiasm. However, I think the task I have outlined is supremely exciting, and much needed, and I suggest that we embark upon this mission with energy and integrity. If we fall short of constructing a tight theoretical paradigm and "merely" succeed in exploring more fully the interfaces between the foundational disciplines in an oM setting, our field and our students will benefit. $^{1}$

\footnotetext{
' I thank Professor LaRue Hosmer of the University of Michigan for emphasizing the left-hand side of the equation, Professor J. Michael Harrison of Stanford University for articulating the intuitive power of the PollacekKinchine formula, Professor John Hooker of Carnegie Mellon University for his thoughtful contributions to theory building, Professor Leroy Schwarz of Purdue University for encouraging me to articulate this vision, and three diligent referees and Professor Kalyan Singhal for careful and thoughtful advice and commentary.
}

\section{References}

Beauchamp, T. AND N. Bowte (1988), Ethical Theory and Business, Prentice-Hall, Englewood Cliffs, NJ. BoINEY, L. (1995), "When Efficient is Insufficient: Fairness in Decisions Affecting a Group," Management Science, 41, 9, 1523-1537.

Burns, T. AND G. STALKER (1961), The Management of Innovation, Tavistock Publications, London, UK.

Dittman, D., H. Juris, AND L. Revsine (1976), "On the Existence of Unrecorded Human Assets: An Economic Perspective," Journal of Accounting Research, 14, 1, 49-65.

Flamholtz, E. (1985), Human Resource Accounting, Jossey-Bass, San Francisco.

- AND R. COFF (1994), "Human Resource Valuation and Amortization in Corporate Acquisitions: A Case Study." Advances in Management Accounting, 3, 55-83.

Galbratth, J. (1973), Designing Complex Organizations, Addison-Wesley, Menlo Park, CA.

Gersick, C. (1988), "Time and Transition in Work Teams: Toward a New Model of Group Development," Academy of Management Journal, 31, 1, 9-41.

(1991), "Revolutionary Change Theories: A Multilevel Exploration of the Punctuated Equilibrium Paradigm," Academy of Management Review, 16, 1, 10-36.

HACKMAN, R., K. BROUSSEAU, AND J. WEISS (1976), "The Interaction of Task Design and Group Performance Strategies in Determining Group Effectiveness," Organizational Behavior and Human Performance, 16, 350-365.

Hackman, J. R. AND G. Oldham (1976), "Motivation through the Design of Work: Test of a Theory," Organizational Behavior and Human Performance, 16, 250-279.

Heyman, D. AND M. Sobel (1984), Stochastic Models in Operations Research, Vol. II, McGraw Hill, New York.

Hooker, J. (1991), Is Design Theory Possible? Working Paper, Graduate School of Industrial Administration, Carnegie Mellon University, Pittsburgh, PA.

HOSMER, L. (1994), Moral Leadership in Business, Irwin, Burr Ridge, IL.

LITTERER, J. (ed.) (1969), Organizations: Structure and Behavior, Vol. I, John Wiley and Sons, New York.

MACDUfFIE, J. AND J. KRAFCIK (1992), "Integrating Technology and Human Resources for High Performance Manufacturing: Evidence from the International Automobile Industry" in Transforming Organizations, T. Kochan and M. Unseem (eds.), Oxford University Press, London, 209-226.

MaRCh, J. AND H. SmON (1958), Organizations, John Wiley and Sons, New York.

OuCHI, W. (1981), Theory Z, Addison-Wesley, Menlo Park, CA.

PASMORE, J. (1988), Designing Effective Organizations: The Sociotechnical Systems Perspective, John Wiley \& Sons, NY.

Robertson, D., K. UlRich, AND M. FILERMAN (1991), "CAD and Cognitive Complexity: Beyond the Drafting Board Metaphor," Manufacturing Review, 4, 3, 194-204.

Schmotter, J. (1984), “An Interview with Professor James E. Howell," Selections, Spring, 3-9.

SchwarZ, L. B. (1996), “The I/C/B Portfolio," Talk delivered at Production and Operations Management Conference, Indianapolis, IN.

SPEARMAN, M. AND W. HoPP (1995), Factory Physics: Foundations of Manufacturing Management, Irwin, Homewood, IL. 
Stalk, G. AND T. Hout (1990), Competing Against Time: How Time-Based Competition is Reshaping Global Markets. The Free Press, New York.

Thompson, J. D. (1967), Organizations in Action, McGraw-Hill, New York.

TRIST, E. AND K. BAMFORTH (1951), “Some Social and Psychological Consequences of the Longwall Method of Coal-Getting," Human Relations, 4, 1, 3-38.

Tuckman, B. ( 1965), "Developmental Sequence in Small Groups," Psychological Bulletin, 63, 6, 384-399.

Velasquez, M. (1992), Business Ethics, Prentice-Hall, Englewood Cliffs, NJ.

Woodruff, R. (1970), “Human Resource Accounting," Canadian Chartered Accountant, September, 156161.

WoodWARD, J. (1965), Industrial Organization: Theory and Practice, Oxford University Press, London. 